NBER WORKING PAPER SERIES

\title{
REAL EXCHANGE RATE TARGETING AND \\ MACROECONOMIC INSTABILITY
}

\author{
Martín Uribe \\ Working Paper 9294 \\ http://www.nber.org/papers/w9294 \\ NATIONAL BUREAU OF ECONOMIC RESEARCH \\ 1050 Massachusetts Avenue \\ Cambridge, MA 02138 \\ October 2002
}

I would like to thank for comments Caroline Betts, David Bowman, Guillermo Calvo, Stephanie SchmittGrohé, and seminar participants at UCLA, the Board of Governors of the Federal Reserve System, the 1995 meeting of the Society for Economic Dynamics and Control held in Barcelona, the 1995 meeting of the Allied Social Sciences Association held in Washington, DC, and the conference Indeterminacy and Sunspots in Macroeconomics held at New York University in November 1997. The views expressed herein are those of the authors and not necessarily those of the National Bureau of Economic Research.

(C) 2002 by Martín Uribe. All rights reserved. Short sections of text, not to exceed two paragraphs, may be quoted without explicit permission provided that full credit, including (C) notice, is given to the source. 
Real Exchange Rate Targeting and Macroeconomic Instability Martín Uribe

NBER Working Paper No. 9294

October 2002

JEL No. F41

\title{
ABSTRACT
}

Using an optimizing model of a small open economy, this paper studies the macroeconomic effects of PPP rules whereby the government increases the devaluation rate when the real exchange rate-defined as the price of tradables in terms of nontradables - is below its long-run level and reduces the devaluation rate when the real exchange rate is above its long-run level. The paper shows that the mere existence of such a rule can generate aggregate fluctuations due to self-fulfilling revisions in expectations. The result is shown to obtain in both flexible- and sticky-price environments.

\author{
Martín Uribe \\ Department of Economics \\ University of Pennsylvania \\ 3718 Locust Walk \\ Philadelphia, PA 19104-6297 \\ and NBER \\ uribe@econ.upenn.edu
}




\section{Introduction}

In developing countries, policymakers often link the rate of devaluation of the domestic currency to the level of the real exchange rate with the intention of maintaining a desired level of competitiveness in foreign markets. Devaluations often take place when the real exchange rate is overvalued, that is, when the relative price of tradables in terms of nontradables is low relative to a target or trend level. Empirical support for this observation is robust. Klein and Marion (1997), for example, analyze 61 episodes of exchange rate management drawn from 16 Latin American countries and Jamaica. They find strong evidence that a more appreciated real exchange rate is associated with a higher likelihood of a devaluation. Similar relationships have been found by Frankel and Rose (1996) and by Kaminsky and Reinhart (1999) for a large number of developing countries. Calvo, Reinhart, and Végh (1995) review the empirical literature on real exchange rate targeting and conclude that the real exchange rate is perhaps the most popular real target in developing countries.

The purpose of this paper is to theoretically study the macroeconomic effects of exchangerate rules whereby the government increases the devaluation rate when the real exchange rate is below its long-run level and decreases it when the real exchange rate is above its long-run level. We refer to this type of rule as purchasing-power-parity (PPP) rules. In particular, the paper focuses on the question of whether the mere adherence to a PPP rule can generate endogenous aggregate instability by allowing for the existence of equilibria in which non-fundamental signals affect the course of the economy. The central result of this investigation is that tight PPP rules can generate indeterminacy of the rational expectations equilibrium and endogenous fluctuations due to arbitrary revisions in expectations. Thus, PPP rules can give rise to situations in which exchange rate instability, both nominal and real, occurs simply because the public expect it. This instability is shown to be welfare decreasing.

We begin by formalizing this idea in a simple perfect-foresight, flexible-price environment. We embed a PPP rule in a model of a small open, monetary economy in which the use of 
money is motivated by assuming that it facilitates transactions à la Kimbrough (1986). The key to understanding the intuition behind our indeterminacy result lies in the relationship between the current level of the real exchange rate and expected devaluations implied by the model. In a small open economy, the nominal interest rate is, loosely speaking, an increasing function of the expected devaluation rate. Hence, an increase in next period's expected devaluation rate causes an increase in the domestic interest rate in the current period. In response to an increase in the nominal interest rate, agents reduce their demand for real money balances. A lower demand for money, in turn, pushes transaction costs up and induces agents to reduce their current consumption expenditure. Given the supply of nontradables, this decline in aggregate consumption puts downward pressure on the relative price of nontradables, that is, it generates a real depreciation of the domestic currency. Thus, expectations of higher future devaluation rates are associated with current real exchange rate depreciation. Consider now a negatively serially correlated sunspot variable and assume that economic agents associate high values of the sunspot variable with high current devaluation rates and low values of the sunspot variable with low current devaluation rates. Then a high realization of the sunspot variable today induces people to believe that next period's devaluation rate will be small, generating, by the mechanism described above, a decrease in the current real exchange rate. By the PPP rule, the government is then induced to devalue the domestic currency in the current period. If the PPP rule is sensitive enough, the current deviation of the devaluation rate from its steady-state level will be larger, in absolute value, than the one expected for next period, making the expectations about the future devaluation rate self-fulfilling.

The perfect-foresight, flexible-price model is a simple vehicle to convey the idea that real exchange rate targeting can have unintended consequences. However, that simple theoretical environment abstracts from two important elements that characterize and motivate the use of PPP rules. First, in reality even governments that explicitly state their intention to target a desired level of real competitiveness do not follow deterministic exchange rate rules. 
In particular, not every episode of real overvaluation is followed by a depreciation of the domestic currency. Our next step is therefore to augment the basic framework to allow for stochastic PPP rules. Under this type of rule, deviations of the real exchange rate from its target level induce a corrective nominal exchange rate movement with a certain probability. Just as in the case of deterministic PPP rules, stochastic rules can induce endogenous instability. The case of stochastic rules is of interest because it shows that external crises can be policy induced even if the nominal exchange rate remains stable throughout the crisis. The key element causing aggregate instability is agents' perception that the government might intervene in the event of a worsening of competitiveness.

A second unrealistic element of the benchmark framework is the assumption that prices are flexible. After all, the main motivation for the introduction of exchange rate rules is that in the presence of nominal rigidities fixed exchange rates introduce real rigidity. Any shock that calls for a movement in the equilibrium real exchange rate induce, in the absence of accommodating exchange rate policies, inefficient adjustment in output and employment. To address this issue, we develop a model with sticky prices à la Rotemberg (1982). We find that, as in the case of flexible prices, the introduction of a PPP rule opens the door to aggregate fluctuations driven solely by self-fulfilling expectations.

Our central result suggests a policy tradeoff. On the one hand, in a world where nominal rigidities are significant, a PPP rule might introduce the necessary real flexibility to cope with intrinsic (fundamental) uncertainty. On the other hand, tight PPP rules can give rise to aggregate fluctuations driven by extrinsic (non-fundamental) uncertainty.

Thus far, the theoretical literature on real exchange rate targeting has focused on the first part of the tradeoff described above. That is, on the role of PPP rules as absorbers of fundamental shocks. For example, Dornbusch (1982) studies PPP rules in a MundellFleming model of a small open economy with sticky wages à la Taylor. In his model, movements in the real exchange rate affect prices and aggregate quantities through both the demand channel (by altering net exports), and the supply channel (by changing the cost of 
tradable inputs). Dornbusch shows that when this model is hit by supply shocks, PPP rules increase the volatility of output if the supply channel dominates and reduces it if the demand channel dominates. Price volatility, on the other hand, always increases with tighter PPP rules. More recently, Calvo et al. . (1995) use a continuous time, cash-in-advance model to show that the government can generate a more depreciated real exchange rate by generating a temporary increase in the devaluation rate. However, they show that the resulting gain in competitiveness is also transitory.

The remainder of the paper is organized as follows. Section 2 presents the basic model. Section 3 derives the central indeterminacy result. As a byproduct, this section presents a technical result that can be of use more generally. Specifically, it develops a technique for establishing determinacy in non-hyperbolic model, that is, models whose equilibrium law of motion contains a unit root. In this class of model, the usual technique to characterize local determinacy, consisting in linearizing around a steady state and studying the eigenvalues of the Jacobian matrix is not valid. Section 4 analyzes stochastic PPP rules. Section 5 studies the consequences of real exchange rate targeting in the presence of sluggish price adjustment. Section 6 concludes.

\section{The Basic Model}

This section embeds a simple PPP rule of the type analyzed in Dornbusch (1982) in a standard optimizing monetary model of a small open economy.

\subsection{The PPP rule}

Let $e_{t}$ denote the real exchange rate in period $t$, defined as the price of tradables in terms

of nontradables. Specifically, letting $P_{t}^{T}$ and $P_{t}^{N}$ denote, respectively, the domestic nominal prices of tradable and non-tradable goods, then the real exchange rate is given by $e_{t}=$ $P_{t}^{T} / P_{t}^{N}$. Throughout the paper, we assume that the law of one price holds for tradables. 
That is, that $P_{t}^{T}=\mathcal{E}_{t} P_{t}^{T *}$, where $\mathcal{E}_{t}$ denotes the nominal exchange rate, defined as the price of foreign currency in terms of domestic currency, and $P_{t}^{T *}$ denotes the international price of tradables. Furthermore, we assume that the foreign-currency price of tradables is constant and normalized to one. These two assumptions imply that the price of one unit of the traded good in terms of domestic currency is always equal to the nominal exchange rate, or $P_{t}^{T}=\mathcal{E}_{t}$. Let $\epsilon_{t} \equiv \mathcal{E}_{t} / \mathcal{E}_{t-1}-1$ denote the devaluation rate in period $t$. The PPP rule is then assumed to be given by

$$
\epsilon_{t}=f\left(e_{t}\right) ; \quad f^{\prime} \leq 0,
$$

where $f$ is a continuously differentiable, non-increasing function. According to this rule, the government increases the rate of devaluation when the real exchange rate appreciates and reduces the devaluation rate when the real exchange rate depreciates.

\subsection{Households}

The economy is assumed to be populated by a large number of identical, infinitely-lived consumers with preferences defined over sequences of consumption of tradables, $c_{t}^{T}$, and nontradables, $c_{t}^{N}$, and described by the utility function

$$
\sum_{t=0}^{\infty} \beta^{t} U\left(c_{t}^{T}, c_{t}^{N}\right),
$$

where $\beta \in(0,1)$ denotes the subjective discount factor, and $U(\cdot, \cdot)$ denotes the single-period utility function, which is assumed to be strictly increasing, strictly concave, and twice continuously differentiable.

Households have access to two types of financial asset, fiat money and an internationally traded bond. This bond is denominated in foreign currency pays the exogenous and constant interest rate $r$ in terms of tradables. To avoid inessential long-run dynamics we assume that 
$r$ satisfies

$$
\beta(1+r)=1
$$

As in Kimbrough (1986), money is assumed to reduce transaction costs in goods markets. Specifically, let $s_{t}$ denote this transaction cost measured in terms of tradables. Then we assume that

$$
s_{t}=v\left(x_{t}, m_{t}^{d}\right)
$$

where $m_{t}^{d}$ and $x_{t}$ denote, respectively, real money balances and consumption expenditure in period $t$, both measured in terms of tradables; $x_{t}$ is defined as

$$
x_{t}=c_{t}^{T}+\frac{c_{t}^{N}}{e_{t}}
$$

In turn, real money holdings are given by $m_{t}^{d}=M_{t}^{d} / P_{t}^{T}$, where $M_{t}^{d}$ denotes the demand for nominal money balances. The transaction cost function $v(\cdot, \cdot)$ is assumed to be increasing in its first argument, decreasing in its second argument, convex, and homogeneous of degree one. ${ }^{1}$ It follows that $v_{x m}<0$. As will become clear shortly, the homogeneity and convexity assumptions imply that the household's demand for real balances is decreasing in the nominal interest rate and unit elastic with respect to expenditure.

The consumer starts each period with some financial assets carried over from the previous period and is endowed with constant amounts of traded and nontraded goods, $y^{T}$ and $y^{N}$. The household's period-by-period budget constraint, expressed in terms of tradables, is then

\footnotetext{
${ }^{1}$ These restrictions on the form of the transaction cost technology are commonplace both in open and closed economy models (see, for example, Rebelo and Végh, 1995; Reinhart and Végh, 1995; and the discussion and references cited in Arrau et al., 1995).
} 
given by,

$$
d_{t}^{c}=(1+r) d_{t-1}^{c}-\frac{m_{t-1}^{d}}{1+\epsilon_{t}}-y^{T}-\frac{y^{N}}{e_{t}}+m_{t}^{d}+x_{t}+s_{t}-\tau_{t}
$$

where $d_{t}^{c}$ denotes the stock of private debt in period $t$, and $\tau_{t}$ is a lump-sum transfer received from the government. The consumer is also assumed to be subject to the following borrowing constraint that prevents him from engaging in Ponzi games,

$$
\lim _{t \rightarrow \infty} \frac{d_{t}^{c}}{(1+r)^{t}} \leq 0
$$

Optimal plans for consumption and asset holdings satisfy the following conditions:

$$
\begin{gathered}
\frac{U_{T}\left(c_{t}^{T}, c_{t}^{N}\right)}{1+v_{x}\left(x_{t}, m_{t}^{d}\right)}=\frac{U_{T}\left(c_{t+1}^{T}, c_{t+1}^{N}\right)}{1+v_{x}\left(x_{t+1}, m_{t+1}^{d}\right)}, \\
e_{t}=\frac{U_{T}\left(c_{t}^{T}, c_{t}^{N}\right)}{U_{N}\left(c_{t}^{T}, c_{t}^{N}\right)}, \\
-v_{m}\left(x_{t}, m_{t}^{d}\right)=\frac{i_{t}}{1+i_{t}},
\end{gathered}
$$

and

$$
\lim _{t \rightarrow \infty} \frac{d_{t}^{c}}{(1+r)^{t}}=0
$$

where $U_{j}, j=T, N$ denotes the marginal utility of good $j$, and $i_{t}$ denotes the domestic nominal interest rate. We assume that the country enjoys perfect capital mobility. Then, under perfect foresight uncovered interest parity must hold

$$
1+i_{t}=(1+r)\left(1+\epsilon_{t+1}\right)
$$


The interpretation of the household's optimality conditions is straightforward. Condition (4) is an Euler equation showing how the presence of transaction costs affects the intertemporal price of consumption. For example, all other things equal, when the marginal transaction cost $v_{x}(x, m)$ is expected to increase over time, consumption tends to display a decreasing pattern. Equation (5) states that agents allocate their expenditure to tradables and non-tradables in such a way that the marginal rate of substitution between these two types of goods equals the real exchange rate. As tradables become more expensive relative to nontradables (i.e., as $e_{t}$ increases) households consume relatively more nontradables and less tradables. Condition (6) is a money demand equation. Because $v(x, m)$ is assumed to be homogeneous of degree one, we have that $v_{m}(x, m)$ is homogeneous of degree zero. It then follows that real balances are unit elastic with respect to total expenditure, $x_{t}$. This implication is in line with money demand estimates in developing countries, as documented, for example, by Arrau et al. (1995), Reinhart and Végh (1995), and Mendoza and Uribe (2000). ${ }^{2}$ Note that the demand for money implicit in equation (6) is decreasing in the nominal interest rate if and only if $v_{m x}<0$. This condition is satisfied given our maintained assumptions of linear homogeneity and convexity of the function $v(\cdot, \cdot) .{ }^{3}$ Thus, we can rewrite equation (6) as

$$
m_{t}^{d}=x_{t} \ell\left(i_{t}\right)
$$

where $\ell(\cdot)$ is strictly decreasing. Finally, equation $(7)$ is a transversality condition stating that private debt must converge to zero in present discounted value.

\footnotetext{
${ }^{2}$ Arrau et al. (1995) estimate money demand functions for ten developing countries. They report an average income elasticity of 1.06 over seven countries for which a cointegrating relationship was found (see table 4). Reinhart and Végh (1995) estimate money demand functions for Argentina, Chile, and Uruguay and find an average consumption elasticity of 1.2 .

${ }^{3} \mathrm{~A}$ negative interest elasticity of money demand is strongly supported by the data (see Reinhart and Végh, 1995; and Arrau et al., 1995). We note, however, that in the presence of currency substitution, a phenomenon that is prevalent in high-inflation economies, there is no guarantee that the money demand function is invariant to alternative policy specifications (see, for instance, Uribe (1997).
} 


\subsection{The government}

The budget constraint of the government is given by

$$
\begin{gathered}
d_{t}^{g}=(1+r) d_{t-1}^{g}-m_{t}^{s}+\frac{m_{t-1}^{s}}{1+\epsilon_{t}}+\tau_{t} \\
\lim _{t \rightarrow \infty} \frac{d_{t}^{g}}{(1+r)^{t}}=0
\end{gathered}
$$

where $d_{t}^{g}$ denotes the stock of public debt and $m_{t}^{s}$ the money supply in $t$, both expressed in terms of tradables. The real money supply is given by $m_{t}^{s}=M_{t}^{s} / P_{t}^{T}$, where $M_{t}^{s}$ denotes the nominal supply of money. As in the case of the household, the government is subject to a borrowing constraint that prevents it from engaging in Ponzi games. Monetary policy is given by the PPP rule (1). Fiscal policy consists of an endogenous sequence of lump-

sum transfers $\left\{\tau_{t}\right\}_{t=0}^{\infty}$ that guarantees that the government's transversality condition (11) is satisfied under all circumstances.

\subsection{Market-clearing conditions}

In equilibrium, the markets for money and nontraded goods must clear

$$
m_{t}^{d}=m_{t}^{s}
$$

and

$$
c_{t}^{N}=y^{N}
$$

We ignore the wealth effects associated with inflation by assuming that the transaction cost, $s_{t}$, is rebated to the representative household in a lump-sum fashion. ${ }^{4}$ This assumption,

\footnotetext{
${ }^{4}$ One can think of $s_{t}$ as representing pure profits of financial institutions owned by households.
} 
together with the two market-clearing conditions and the budget constraints of the household and of the government imply that the country's consolidated foreign debt, $d_{t} \equiv d_{t}^{c}+d_{t}^{g}$, evolves according to the following expression

$$
d_{t}=(1+r) d_{t-1}-y^{T}+c_{t}^{T}
$$

This expression and the terminal conditions (7) and (11) are equivalent to the following intertemporal resource constraint:

$$
\sum_{t=0}^{\infty} \frac{c_{t}^{T}}{(1+r)^{t}}=a_{0},
$$

where $a_{0} \equiv(1+r)\left(y^{T} / r-d_{-1}\right)$ denotes the country's wealth in period zero. Combining equations (4), (8), (9), and (12) and taking into account that $v_{x}(x, m)$ is homogeneous of degree zero in $x$ and $m$, yields

$$
\frac{U_{T}\left(c_{t}^{T}, y^{N}\right)}{h\left(\epsilon_{t+1}\right)}=\frac{U_{T}\left(c_{t+1}^{T}, y^{N}\right)}{h\left(\epsilon_{t+2}\right)}
$$

where $h(\epsilon) \equiv 1+v_{x}(1, \ell((1+r)(1+\epsilon)-1)$ is strictly increasing in $\epsilon$. Equations (5) and (12) together with the assumed strict concavity of the single-period utility function imply that the equilibrium real exchange rate is a strictly decreasing function of the level of consumption of tradables, ${ }^{5}$

$$
e_{t}=g\left(c_{t}^{T}\right) ; \quad g^{\prime}<0
$$

We are now ready to provide a formal definition of equilibrium.

Definition 1 A perfect-foresight equilibrium is a set of sequences $\left\{c_{t}^{T}, e_{t}, \epsilon_{t}\right\}_{t=0}^{\infty}$ satisfying (1), (14), (15), and (16), given $a_{0}$.

\footnotetext{
${ }^{5}$ This relationship and the policy rule (1) imply that in this economy targeting the real exchange rate is equivalent to targeting the trade balance.
} 


\section{$3 \quad$ Equilibrium dynamics}

Before studying the consequences of PPP rules, it will prove instructive to consider a benchmark scenario in which the monetary authority pegs the rate of devaluation.

\subsection{Equilibrium under a constant devaluation rate}

Assume that at $t=0$ the central bank announces a monetary policy by which the devaluation rate is set at a constant level $\epsilon_{*}$ for all $t$. Under this policy specification, a perfect-foresight equilibrium is defined as a pair of sequences $\left\{c_{t}^{T}, e_{t}\right\}_{t=0}^{\infty}$ satisfying (14), (15), and (16), given $a_{0}$ and $\epsilon_{t}=\epsilon_{*}$ for all $t$. It then follows from equilibrium condition (15) that

$$
U_{T}\left(c_{t}^{T}, y^{N}\right)=U_{T}\left(c_{t+1}^{T}, y^{N}\right)
$$

Since $U_{T}\left(c^{T}, y^{N}\right)$ is a monotone function of $c^{T}$, it follows that in equilibrium consumption

of tradables must be constant over time, that is, $c_{t}^{T}=c_{t+1}^{T}$ for $t \geq 0$. Equation (14) then implies that the equilibrium level of consumption of tradables, $c_{*}^{T}$, is unique and given by

$$
c_{*}^{T}=\frac{r}{1+r} a_{0}
$$

Households consume their permanent income at all times. This unique equilibrium is in fact Pareto optimal, for $c_{t}^{T}=c_{*}^{T}$ represents the solution to the problem of maximizing the representative consumer's utility function subject to the resource constraints (12) and (14). As the analysis that follows makes clear, this equilibrium outcome is in sharp contrast with the ones that may emerge under real exchange rate targeting. 


\subsection{Equilibrium under real exchange rate targeting}

Assume now that the government follows an active PPP rule as described by equation (1), with $f^{\prime}<0$. Combining (1), (15), and (16) yields,

$$
\frac{U_{T}\left(c_{t}^{T}, y^{N}\right)}{n\left(c_{t+1}^{T}\right)}=\frac{U_{T}\left(c_{t+1}^{T}, y^{N}\right)}{n\left(c_{t+2}^{T}\right)}
$$

where $n\left(c^{T}\right) \equiv h\left(f\left(g\left(c^{T}\right)\right)\right)$ is a strictly increasing and continuously differentiable function. A perfect foresight equilibrium is then defined as a sequence $\left\{c_{t}^{T}\right\}_{t=0}^{\infty}$, satisfying (14) and (18), given $a_{0}$. Obviously, $c_{t}^{T}=c_{*}^{T} \forall t$, with $c_{*}^{T}$ given by (17), is a perfect foresight equilibrium. However, this economy may admit other equilibria in which endogenous variables fluctuate in response to arbitrary revisions in expectations. This result is formally stated in proposition 1 , which focuses on perfect-foresight equilibria in which all variables remain in a neighborhood of the steady-state equilibrium.

\section{Proposition 1 If}

$$
\frac{n^{\prime}\left(c_{*}^{T}\right)}{n\left(c_{*}^{T}\right)}>-\frac{U_{T T}\left(c_{*}^{T}, y^{N}\right)}{U_{T}\left(c_{*}^{T}, y^{N}\right)},
$$

then there exists an infinite number of equilibria $\left\{c_{t}^{T}\right\}_{t=0}^{\infty}$ that remain close to $c_{*}^{T}$ and converge, although not necessarily to $c_{*}^{T}$.

Before presenting the proof of proposition 1, we note that the standard approach to establishing local indeterminacy consists in examining the eigenvalues of the Jacobian matrix of a linearized version of the equilibrium system. This technique is inappropriate in the economy under study. The reason is that in small open economies with a single bond and an interest rate satisfying $\beta(1+r)=1$, the Jacobian of the equilibrium system possesses a unit root. As a result, there is a breakdown of the theoretical link that ensures that the dynamic properties of the linearized system are locally identical to those of the original, nonlinear system. ${ }^{6}$ An

\footnotetext{
${ }^{6}$ See, for example, Azariadis, 1993, ch. . 6.
} 
alternative approach is therefore needed to characterize local dynamics. This is the focal concern in the proof of proposition 1.

Proof: Condition (19) and the fact that both $U_{T}(\cdot, \cdot)$ and $n(\cdot)$ are $C^{1}$ functions imply that .one can construct an interval $I_{1} \equiv\left[c_{*}^{T}-\alpha_{1}, c_{*}^{T}+\alpha_{1}\right]$ with $\alpha_{1}>0$, such that if $c^{T} \in I_{1}$ then

$$
\frac{n^{\prime}\left(c^{T}\right)}{n\left(c^{T}\right)}>-\frac{U_{T T}\left(c^{T}, y^{N}\right)}{U_{T}\left(c^{T}, y^{N}\right)}
$$

Also, for any $c^{T} \in I_{1}$, one can find a scalar $\epsilon\left(c^{T}\right)>0$ such that for any initial condition $\left(c_{0}^{T}, c_{1}^{T}\right)$ satisfying $\left|\left(c_{0}^{T}, c_{1}^{T}\right)-\left(c^{T}, c^{T}\right)\right|<\epsilon\left(c^{T}\right)$ and

$$
\frac{U_{T}\left(c_{0}^{T}\right)}{n\left(c_{1}^{T}\right)}=\frac{U_{T}\left(c^{T}\right)}{n\left(c^{T}\right)}
$$

the sequence $\left\{c_{t}^{T}\right\}_{t=0}^{\infty}$ generated by the second order difference equation (18) converges to $c^{T}$. Moreover, the resulting sequence is bonded by $\left(c^{T}-\epsilon\left(c^{T}\right), c^{T}+\epsilon\left(c^{T}\right)\right)$. Because $I_{1}$ is closed and bounded, $\alpha_{2} \equiv \inf \left\{\epsilon\left(c^{T}\right): c^{T} \in I_{1}\right\}$ can be taken to be positive. Consider the set of pairs $I_{2} \equiv\left\{\left(c_{0}^{T}, c_{1}^{T}\right):\left(c_{0}^{T}, c_{1}^{T}\right) \in I_{1} \times I_{1}\right.$ and $\left.\left|c_{0}^{T}-c_{1}^{T}\right|<\alpha_{2}\right\}$. Note that $I_{2}$ is convex. Clearly, for any initial condition $\left(c_{0}^{T}, c_{1}^{T}\right) \in I_{2}$, the difference equation (18) generates a sequence $\left\{c_{t}^{T}\right\}_{t=0}^{\infty}$ that is bounded by $I_{1}$ and converges. If such sequence satisfies equation (14), it constitutes a perfect foresight equilibrium. One can regard each element of a sequence generated by equation (18) as a function of the initial condition $\left(c_{0}^{T}, c_{1}^{T}\right)$, and use the notation $c_{t}^{T}\left(c_{0}, c_{1}\right)$ to refer to the $t$-th element of the sequence. Since both $U_{T}(\cdot, \cdot)$ and $n(\cdot)$ are continuous functions, $c_{t}^{T}(\cdot, \cdot)$ is also continuous. Take any $\left(c_{0}^{T}, c_{1}^{T}\right) \in I_{2}$. Then, because $c_{t}^{T}\left(c_{0}^{T}, c_{1}^{T}\right)$ is bounded by $I_{1}$ and $(1+r)^{-1} \in(0,1)$, it follows that the sequence of partial sums

$$
A_{t}\left(c_{0}^{T}, c_{1}^{T}\right) \equiv \sum_{j=0}^{t}(1+r)^{-j} c_{j}^{T}\left(c_{0}^{T}, c_{1}^{T}\right) ; \quad t \geq 0
$$

converges uniformly to a continuous function $A\left(c_{0}^{T}, c_{1}^{T}\right)$ as $t \rightarrow \infty$ (Rudin, 1976, ch. . 7). Finding an equilibrium then reduces to finding pairs $\left(c_{0}^{T}, c_{1}^{T}\right)$ such that $A\left(c_{0}^{T}, c_{1}^{T}\right)=a_{0}$. To 
see that there are infinitely many such pairs, take any scalar $\theta \in\left(0, \alpha_{1}\right)$, and note that

$$
A\left(c_{*}^{T}-\theta, c_{*}^{T}-\theta\right)=a_{0}-\frac{1+r}{r} \theta<a_{0}<a_{0}+\frac{1+r}{r} \theta=A\left(c_{*}^{T}+\theta, c_{*}^{T}+\theta\right)
$$

Since $A(\cdot, \cdot)$ is continuous, one can find a continuum of scalars $\phi \in\left(0, \alpha_{1}-\theta\right)$, such that

$$
A\left(c_{*}^{T}-\theta+\phi, c_{*}^{T}-\theta\right)<a_{0}<A\left(c_{*}^{T}+\theta+\phi, c_{*}^{T}+\theta\right) .
$$

Since $A(\cdot, \cdot)$ is continuous, there exists a linear combination of $\left(c_{*}^{T}-\theta+\phi, c_{*}^{T}-\theta\right)$ and $\left(c_{*}^{T}+\theta+\phi, c_{*}^{T}+\theta\right)$ for which $A(\cdot, \cdot)$ takes the value $a_{0}$. Since no such linear combination equals $\left(c_{*}^{T}, c_{*}^{T}\right)$, the equilibrium found is different from $c_{t}^{T}=c_{*}^{T} \forall t$. Moreover, because there exists a continuum of values of $\phi$ with the properties described above, there exists a continuum of perfect foresight equilibria.

Condition (19) implies that the possibility of indeterminacy of the perfect foresight equilibrium is higher the more elastic the PPP rule, the higher the elasticity of intertemporal substitution, the higher the interest rate elasticity of money demand, and the lower the intratemporal elasticity of substitution between tradables and nontradables. As a way to provide a feeling for the actual magnitude of the sensitivity of the PPP rule required for indeterminacy, we set all other parameters at plausible values and solve for the minimum semielasticity of $f$ for which (19) is satisfied. Assume that the period utility function is of the form $U\left(c^{T}, c^{N}\right)=\left\{\left[a c^{T^{1-1 / \mu}}+c^{N^{1-1 / \mu}}\right]^{\mu /(\mu-1)}\right\}^{1-1 / \sigma} /(1-1 / \sigma)$, so that the intertemporal elasticity of substitution is $\sigma$, and the intratemporal elasticity of substitution between tradables and nontradables is $\mu$. Assume also that the transactions cost function is of the form $s(x, m)=A x^{1+\gamma} m^{-\gamma}$, which implies an elasticity of money demand with respect to $i /(1+i)$ equal to $-1 /(1+\gamma)$. Following Ostry and Reinhart (1992) who use data from developing countries to estimate the three parameters defining our preference specification, we set $\sigma=0.44, \mu=0.93$, and $a=0.58 .^{7}$ At the same time we follow Mendoza and Uribe

\footnotetext{
${ }^{7}$ The values for $\sigma$ and $\mu$ correspond to the average of the estimates for the Latin America region.
} 
(2000) and set $\epsilon=28$ percent per quarter, $r=1.59$ percent per quarter, $e c^{T} / c^{N}=0.55$, $\gamma=5.25$, and $A=0.55$. Mendoza and Uribe (2000) obtain these figures using long-run data relations from the Mexican economy, but similar figures are obtained for other Latin American Economies. Under the above parameterization, the model displays indeterminacy when the semielasticity of the PPP rule, $f^{\prime}(e) e$, is higher than 1.72 in absolute value. That is, when in response to a one percent appreciation of the real exchange rate the government devalues the nominal exchange rate by 1.72 percent or more.

It is worth noting that the equilibrium involving constant consumption $\left(c_{t}^{T}=c_{*}^{T} \forall t\right)$ Pareto dominates all other equilibria. This is because, as discussed earlier, the steady-state equilibrium solves the first-best problem. Thus, in the present model real exchange rate targeting is welfare decreasing. We also note that when condition (20) is satisfied, not only does the path of consumption become indeterminate, but also its steady-state level becomes indeterminate. The indeterminacy of the steady state is a consequence of the unit root built in small open economy models with incomplete asset markets.

\section{Stochastic PPP Rules}

The PPP rule studied thus far assumes that the government adjusts the devaluation rate period by period in its effort to target a given level of real depreciation. In practice, however, governments adjust the nominal exchange rate more sporadically. More importantly, typically private agents do not have certainty regarding the timing of devaluations. A natural question that arises is whether the results obtained in this section regarding the stability of the macroeconomic equilibrium hold under this more realistic environment.

Suppose that the monetary authority introduces corrective devaluations in response to deviations of the real exchange rate from target, but that this interventions are random. 
Specifically, consider a PPP rule of the form

$$
\epsilon_{t}=\left\{\begin{array}{cl}
f\left(e_{t}\right) & \text { with probability } \pi \\
\bar{\epsilon} & \text { with probability } 1-\pi
\end{array}\right.
$$

where $f$ is defined as before and $\bar{\epsilon}$ and $\pi \in[0,1]$ are constant parameters. This new PPP rule is a generalization of the two polar cases considered thus far. In particular, if $\pi=0$, then the monetary authority follows a devaluation rate peg. On the other hand, if $\pi=1$, the government follows a deterministic PPP rule.

Consider the equilibrium conditions associated with this economy. As in the nonstochastic case, the real exchange rate is linked to aggregate spending by the static relation (16). The remaining equilibrium conditions are stochastic versions of, respectively, the Euler equation (15), the Fisher equation (8), and the resource constraint (14):

$$
\begin{gathered}
\frac{U_{T}\left(c_{t}^{T}, y^{N}\right)}{k\left(i_{t}\right)}=E_{t}\left\{\frac{U_{T}\left(c_{t+1}^{T}, y^{N}\right)}{k\left(i_{t+1}\right)}\right\} \\
\frac{U_{T}\left(c_{t}^{T}, y^{N}\right)}{k\left(i_{t}\right)}=\frac{1+i_{t}}{1+r} E_{t}\left\{\frac{U_{T}\left(c_{t+1}^{T}, y^{N}\right)}{k\left(i_{t+1}\right)} \frac{1}{1+\epsilon_{t+1}}\right\} \\
E_{t} \sum_{j=0}^{\infty} \frac{c_{t+j}^{T}}{(1+r)^{j}}=a_{t},
\end{gathered}
$$

where $k(i) \equiv 1+v_{x}(1, \ell(i))$ is strictly increasing in $i$.

This economy admits an infinite number of equilibria in which consumption and the nominal interest rate are nonstochastic. To see this, assume that consumption and the nominal interest rate are indeed nonstochastic. Then, one can rewrite equation (23) using 
(16) and (21) to obtain

$$
(1+r)=\left(1+i_{t}\right)\left\{\frac{\pi}{1+f\left(g\left(c_{t+1}^{T}\right)\right)}+\frac{1-\pi}{1+\bar{\epsilon}}\right\}
$$

This expression defines an increasing function $q: R \rightarrow R$ such that

$$
i_{t}=q\left(c_{t+1}^{T}\right)
$$

Using this relationship, equations (22) and (24) become

$$
\begin{gathered}
\frac{U_{T}\left(c_{t}^{T}, y^{N}\right)}{n\left(c_{t+1}^{T}\right)}=\frac{U_{T}\left(c_{t+1}^{T}, y^{N}\right)}{n\left(c_{t+2}^{T}\right)} \\
\sum_{t=0}^{\infty} \frac{c_{t}^{T}}{(1+r)^{t}}=a_{0} .
\end{gathered}
$$

where $n\left(c^{T}\right) \equiv k\left(q\left(c^{T}\right)\right)$. The newly defined function $n$ is not the same as the one defined under a deterministic PPP rule in the previous section, but it shares the same properties. In particular, the new function $n$ is increasing and smooth. Therefore, the equilibrium conditions under a stochastic PPP rule are qualitatively identical to those obtained in the deterministic case. As a result, we can invoke Proposition 1 to prove that if the function $n$ is more elastic than the function $U_{T}$, then there exists an infinite number of equilibria in which consumption fluctuates deterministically and converges to a steady state. This steady state will in general differ from the level of consumption associated with the steady-state equilibrium, $c_{*}^{T}$.

Although on the surface the dynamic properties of this economy look identical to those associated with the deterministic PPP rule, a number of relevant differences emerge. First, the possibility of aggregate instability caused by self-fulfilling revisions in expectations now depends on the perceived probability of intervention $\pi$. Specifically, the larger $\pi$, the larger 
the elasticity of $n$ and thus the more likely indeterminacy becomes. Second, in the economy studied here the devaluation rate is a random variable. The distribution of $\epsilon_{t}$ is not iid. The distribution is not identical over time because its mean and variance depend on the level of the real exchange rate, which is a time-varying variable. Nor is $\epsilon_{t}$ independently distributed, for the level of the real exchange rate in period $t>0$ depends on the value taken by this variable in period 0 . Finally, the model captures the possibility of expectations-driven movements in the current account and the trade balance in the absence of actual devaluations. This property of the model is of empirical interest. For example, in the aftermath of the Mexican crisis and during the Asian crisis, countries like Argentina and Hong Kong faced marked movements in aggregate spending and external accounts even though they managed to maintain their respective exchange rates unaltered.

\section{$5 \quad$ Sticky Prices}

Perhaps the main reason why policymakers engage in real exchange rate targeting is the need to eliminate the real rigidities that a fixed exchange rate would introduce in an environment with nominal price rigidities. It is thus clearly in order to extend our benchmark economy to allow for price stickiness. Accordingly, consider an economy populated by a continuum of identical infinitely lived households indexed by $j \in[0,1]$. Each household is the monopolistic producer of a differentiated nontraded good $y_{t}^{N}(j)$. This good is produced with labor, using a technology that yields one unit of good per unit of labor. Thus, $y_{t}^{N}(j)$ denotes both the quantity of goods produced and the amount of labor supplied by household $j$ in period $t$. Each household has preferences defined over sequences of consumption of tradables, $c_{t}^{T}(j)$, consumption of nontradables, $c_{t}^{N}(j)$, and labor effort, $y_{t}^{N}(j)$. Nominal rigidities are introduced by assuming that each household derives disutility from changing the price of the good 
it produces, $P_{t}(j)$. Specifically, preferences are described by the following utility function:

$$
\sum_{t=0}^{\infty} \beta^{t}\left[U\left(c_{t}^{T}(j), c_{t}^{N}(j)\right)-V\left(y_{t}^{N}(j)\right)-\frac{\phi}{2}\left(\frac{P_{t}(j)}{P_{t-1}(j)}-1\right)^{2}\right],
$$

where $U(\cdot, \cdot)$ is assumed to be strictly increasing, strictly concave, and twice continuously differentiable. The function $V$ is assumed to be increasing and convex, and $\phi$ is a positive parameter. The nontraded consumption good is a composite of all of the different nontraded varieties produced in the economy and is given by

$$
c_{t}^{N}(j)=\left[\int_{0}^{1} c_{t}^{N}(j, z)^{\frac{\theta-1}{\theta}} d z\right]^{\frac{\theta}{\theta-1}}, \quad \theta>1
$$

where $c_{t}^{N}(j, z)$ denotes household $j^{\prime} s$ demand for good $z$ in period $t$. Each period, the household solves the static problem of minimizing the cost of purchasing the desired amount of the nontraded composite good. Formally, in period $t$ the household chooses $c_{t}^{N}(j, z)$ as the solution to the following problem:

$$
\min \int_{0}^{1} P_{t}(z) c_{t}^{N}(j, z) d z
$$

subject to

$$
\left[\int_{0}^{1} c_{t}^{N}(j, z)^{\frac{\theta-1}{\theta}} d z\right]^{\frac{\theta}{\theta-1}} \geq c_{t}^{N}(j)
$$

The cost-minimizing demand for good $z$ is

$$
c_{t}^{N}(j, z)=c_{t}^{N}(j)\left(\frac{P_{t}(z)}{P_{t}}\right)^{-\theta},
$$


where $P_{t}$ is defined by

$$
P_{t}=\left[\int_{0}^{1} P_{t}(z)^{(1-\theta)} d z\right]^{\frac{1}{1-\theta}}
$$

The price index $P_{t}$ represents the minimum cost of purchasing one unit of the composite good in period $t$.

Household $j$ 's period-by-period budget constraint expressed in terms of tradables is given by

$$
d_{t}^{c}(j)=(1+r) d_{t-1}^{c}(j)-\frac{m_{t-1}^{d}(j)}{\left(1+\epsilon_{t}\right)}-y^{T}-\frac{y_{t}^{N}(j)}{e_{t}} \frac{P_{t}(j)}{P_{t}}+m_{t}^{d}(j)+x_{t}(j)+s_{t}(j)-\tau_{t},
$$

where $d_{t}^{c}(j), m_{t}^{d}(j)$, and $y^{T}$ denote, respectively, real private debt, real money holdings, and a constant endowment of tradables. Consumption expenditure, $x_{t}(j)$, and the transaction cost, $s_{t}(j)$, are defined as in the previous section:

$$
\begin{gathered}
x_{t}(j)=c_{t}^{T}(j)+\frac{c_{t}^{N}(j)}{e_{t}} \\
s_{t}(j)=v\left(x_{t}(j), m_{t}^{d}(j)\right) .
\end{gathered}
$$

In addition, households are subject to the following borrowing constraint:

$$
\lim _{t \rightarrow \infty} \frac{d_{t}^{c}(j)}{(1+r)^{t}} \leq 0
$$

which prevents them from playing Ponzi games.

A key difference between the model economy developed here and the endowment economy studied in previous sections is that now the household/firm unit has the ability to choose the price of the good it supplies monopolistically. Firms must supply as much output as demanded at the price they set. So output is demand determined. Formally, household $j$ 
faces the constraint

$$
y_{t}^{N}(j) \geq c_{t}^{N}\left(\frac{P_{t}(j)}{P_{t}}\right)^{-\theta}
$$

where $c_{t}^{N}\left(\frac{P_{t}(j)}{P_{t}}\right)^{-\theta}$ is the demand faced by the household/firm for the good it produces, and $c_{t}^{N} \equiv \int_{0}^{1} c_{t}^{N}(j) d j$ denotes the aggregate demand for the nontraded composite good.

Household $j$ chooses sequences $\left\{c_{t}^{T}(j), c_{t}^{N}(j), m_{t}^{d}(j), x_{t}(j), y_{t}^{N}(j), s_{t}(j), d_{t}^{c}(j), P_{t}(j)\right\}_{t=0}^{\infty}$, so as to maximize (28) subject to (29)-(33). The first-order conditions associated with this problem are (29), (30), (31), (32) with equality, and:

$$
\begin{gathered}
\frac{U_{T}\left(c_{t}^{T}(j), c_{t}^{N}(j)\right)}{1+v_{x}\left(x_{t}(j), m_{t}^{d}(j)\right)}=\lambda_{t}(j) \\
e_{t}=\frac{U_{T}\left(c_{t}^{T}(j), c_{t}^{N}(j)\right)}{U_{N}\left(c_{t}^{T}(j), c_{t}^{N}(j)\right)} \\
\lambda_{t}(j)=\lambda_{t+1}(j) \\
-v_{m}\left(x_{t}(j), m_{t}^{d}(j)\right)=\frac{i_{t}}{1+i_{t}} \\
0=\theta V^{\prime}\left(y_{t}^{N}(j)\right) y_{t}^{N}(j) \frac{1}{P_{t}(j)}-\phi\left(\frac{P_{t}(j)}{P_{t-1}(j)}-1\right) \frac{1}{P_{t-1}(j)} \\
+\beta \phi\left(\frac{P_{t+1}(j)}{P_{t}(j)}-1\right) \frac{P_{t+1}(j)}{P_{t}(j)^{2}}+(1-\theta) \lambda_{t}(j) \frac{y_{t}^{N}(j)}{e_{t}} \frac{1}{P_{t}},
\end{gathered}
$$

where $\lambda_{t}(j)$ denotes the marginal utility of wealth of household $j$ in period $t$, and $\pi_{t}(j) \equiv$ $P_{t}(j) / P_{t-1}(j)-1$ denotes the inflation rate of good $j$ in period $t$. The nominal interest rate, $i_{t}$, satisfies the uncovered interest parity condition (8). 
We focus on a symmetric equilibrium in which all household/firm units charge the same price for the good they produce. Thus, in equilibrium all households are identical. This means that we can drop the index $j$. In addition, we have that in equilibrium consumption of nontradables must equal production of that type of goods, $y_{t}^{N}=c_{t}^{N}$. By definition, the real exchange rate evolves according to the expression

$$
e_{t}=e_{t-1}\left(\frac{1+\epsilon_{t}}{1+\pi_{t}}\right)
$$

Finally, we assume that the government follows a PPP rule of the form given in (1). To facilitate the analysis, we will assume that the utility function is log-linear in consumption, that is, $U\left(c^{T}, c^{N}\right)=\ln c^{T}+\ln c^{N}$. Then, the equilibrium conditions can be written as

$$
\begin{gathered}
c_{t+1}^{T} n\left(c_{t+2}^{T} / c_{t+2}^{N}\right)=c_{t}^{T} n\left(c_{t+1}^{T} / c_{t+1}^{N}\right) \\
\pi_{t+1}\left(1+\pi_{t+1}\right)=\beta^{-1} \pi_{t}\left(1+\pi_{t}\right)-\frac{\theta}{\beta \phi} V^{\prime}\left(c_{t}^{N}\right) c_{t}^{N}-\frac{(1-\theta)}{\beta \phi} \frac{1}{n\left(c_{t}^{T} / c_{t}^{N}\right)} \\
\frac{c_{t}^{T}}{c_{t}^{N}}=\frac{c_{t-1}^{T}}{c_{t-1}^{N}}\left[\frac{1+\pi_{t}}{1+g\left(\frac{c_{t}^{T}}{c_{t}^{N}}\right)}\right] \\
\sum_{t=0}^{\infty} \frac{c_{t}^{T}}{(1+r)^{t}}=a_{0},
\end{gathered}
$$

where $g(x) \equiv f(1 / x)$ and $n(x) \equiv 1+v_{x}(1, \ell((1+r)(1+g(x))-1))$ are strictly increasing functions, and $\ell(\cdot)$ is the liquidity preference function defined in equation (9). We can now provide a formal definition of a perfect-foresight equilibrium.

Definition 2 A perfect-foresight equilibrium is a set of sequences $\left\{c_{t}^{T}, c_{t}^{N}, \pi_{t}\right\}_{t=0}^{\infty}$ satisfying 
equations (34)-(37), given the initial conditions $a_{0}$ and $c_{-1}^{T} / c_{-1}^{N}$.

Consider first steady-state equilibria. That is, solutions to the system (34)-(37) in which all variables are constant for $t \geq 0$. Let $c_{-1}^{T} / c_{-1}^{N}=c_{*}^{T} / c_{*}^{N}$. Then the triplet $\left(c_{*}^{T}, c_{*}^{N}, \pi_{*}\right)$ represents a steady-state equilibrium if it satisfies the following three conditions:

$$
\begin{gathered}
\pi_{*}=g\left(\frac{c_{*}^{T}}{c_{*}^{N}}\right) \\
\left(\beta^{-1}-1\right) g\left(\frac{c_{*}^{T}}{c_{*}^{N}}\right)=\frac{\theta}{\beta \phi} V^{\prime}\left(c_{*}^{N}\right) c_{*}^{N}+\frac{(\theta-1)}{\beta \phi} \frac{1}{n\left(c_{*}^{T} / c_{*}^{N}\right)} \\
c_{*}^{T}=\frac{r}{1+r} a_{0} .
\end{gathered}
$$

The left hand side of the second equation is strictly decreasing in $c_{t}^{N}$ whereas the right hand side is strictly increasing in $c_{t}^{N}$. Under the weak assumption that $(1-\beta) g(\infty)>\frac{(\theta-1)}{\phi n(\infty)}$, a unique steady-state equilibrium exists. Note that in a steady-state equilibrium consumption of tradables is identical to that obtained in the flexible-price economy.

Now assume that the government follows a devaluation rate peg. In this case $n^{\prime}=0$. Then equation (34) implies that $c_{t+1}^{T}=c_{t}^{T} \forall t$. This result together with the intertemporal resource constraint (37) imply that $c_{t}^{T}=c_{*}^{T} \equiv r a_{0} /(1+r)$ for all $t$. Then equations (35) and (36) jointly determine the equilibrium paths of $\pi_{t}$ and $c_{t}^{N}$. The following proposition shows that there exists a unique solution to this system.

Proposition 2 The perfect foresight equilibrium associated with a devaluation rate peg is locally unique.

Proof: Log-linearizing equations (35) and (36) around $\pi_{*}$ and $c_{*}^{N}$, we obtain:

$$
\hat{\pi}_{t+1}=\beta^{-1} \hat{\pi}_{t}-\gamma \hat{c}_{t}^{N}
$$




$$
\hat{c}_{t}^{N}=-\frac{\pi}{1+\pi} \hat{\pi}_{t}+\hat{c}_{t-1}^{N}
$$

where $\gamma \equiv \frac{\theta V^{\prime} c^{N}}{\beta \phi \pi}\left(1+\eta_{V^{\prime}}\right) \frac{1+\pi}{2+\pi}>0$ and $\eta_{V^{\prime}} \equiv c^{N} V^{\prime \prime} / V^{\prime}$. A hat on a variable denotes its log-deviation from its steady-state value. For simplicity, we assume that $c_{-1}^{T}=c_{*}^{T}$. Using the second equation to eliminate $\hat{c}_{t}^{N}$ from the first yields

$$
\hat{\pi}_{t+1}=\left(\beta^{-1}+\frac{\gamma \pi}{1+\pi}\right) \hat{\pi}_{t}-\gamma \hat{c}_{t-1}^{N}
$$

To establish proposition 2, it suffices to show that the linear system (38)-(39), describing the local dynamics of the vector $\left(\pi_{t} ; c_{t}^{N}\right)$, has a unique solution converging to $\left(\pi_{*}, c_{*}^{N}\right)$. The Jacobian matrix of the system formed by (39) and (38) (in that order) is:

$$
J=\left[\begin{array}{cc}
\left(\beta^{-1}+\frac{\gamma \pi}{1+\pi}\right) & \gamma \\
-\frac{\pi}{1+\pi} & 1
\end{array}\right]
$$

Because the system has one predetermined variable, $\hat{c}_{t-1}^{N}$, and one nonpredetermined variable, $\hat{\pi}_{t}$, local uniqueness requires that one eigenvalue of $J$ lies inside the unit circle and the other outside. Let $\lambda_{1}$ and $\lambda_{2}$ be the eigenvalues of $J$. Letting $T$ and $D$ denote the trace and determinant of $J$, respectively, we have that $\lambda_{1}+\lambda_{2}=T$ and $\lambda_{1} \lambda_{2}=D$. Also, $T=$ $1+\beta^{-1}+x>2$, with $x \equiv \frac{\gamma \pi}{1+\pi}>0$, and $D=\beta^{-1}>1$. Because $D>0$ and $T>0$, the real parts of both eigenvalues are positive. In addition, because $D>1$, at least one eigenvalue lies outside the unit circle. It is also the case that both eigenvalues are real. To establish this, recall that $\lambda_{1}$ and $\lambda_{2}$ are the solutions to the quadratic equation $0=\lambda^{2}-T \lambda+D$. Then we must show that $T^{2}-4 D>0$. We have that $T^{2}=1+2 \beta^{-1}+\beta^{-2}+x_{1}$, where $x_{1} \equiv x^{2}+2 \beta^{-1} x+2 x>0$. Then $T^{2}-4 D=1-2 \beta^{-1}+\beta^{-2}+x_{1}=\left(1-\beta^{-1}\right)^{2}+x_{2}>0$. Finally, suppose that both eigenvalues are greater than 1 . Let $\lambda_{1}$ denote the smaller eigenvalue. Then $\lambda_{1}=\left(T-\sqrt{T^{2}-4 D}\right) / 2$. Thus, $\lambda_{1}>1$ implies $(T-2)^{2}>T^{2}-4 D$, or $T^{2}-4 T+4>T^{2}-4 D$, or $-4 T+4>-4 D$. This implies that $-4-4 \beta^{-1}-4 x+4>-4 \beta^{-1}$, or $-4 x>0$, which is 
a contradiction.

Proposition 2 establishes that endogenous fluctuations near the steady state are impossible when the government pegs the devaluation rate at all times. By contrast, once the government engages in real exchange rate targeting the possibility of endogenous aggregate instability emerges. Establishing this possibility is the focus of proposition 3.

Proposition 3 If the elasticity of the PPP rule is sufficiently large, then the perfect foresight equilibrium may become indeterminate. In this case, there exists an infinite number of equilibrium sequences $\left\{c_{t}^{T}, c_{t}^{N}, \pi_{t}\right\}_{t=0}^{\infty}$ originating in the neighborhood of the steady-state equilibrium $\left(c_{*}^{T}, c_{*}^{N}, \pi_{*}\right)$ and converging to a constant allocation $\left(c^{T}, x, \pi\right)$ that is not necessarily equal to $\left(c_{*}^{T}, c_{*}^{N}, \pi_{*}\right)$.

Proof: See the appendix.

\section{Discussion and Conclusion}

The characterization of possible channels through which real-exchange-rate targeting affects the macroeconomy is central to understanding business cycles in emerging economies. This is because, Calvo et al. (1995) put it, "[b]eing a key relative price in any open economy, the real exchange rate is probably the most popular real target in developing economies." This is particularly the case in Latin America. Calvo et al. provide three examples of actual episodes of real exchange-rate targeting in this region. An early one is Brazil, where in 1968 the central bank made explicit a rule by which the exchange rate was adjusted as a function of the difference between domestic and U.S. inflation. Maintaining purchasing power parity has been at center stage of the Brazilian exchange-rate policy ever since. In Chile, between 1985 and 1992, the government maintained the exchange rate within a band whose trend was set as a function of the difference between the previous month's inflation rate and a measure of average inflation in the rest of the world. Colombia, too, followed an explicit PPP rule between 1986 and 1990. 
On the theoretical front, the main insight of a large existing literature on real exchange rate targeting, clearly exemplified by Dornbusch (1982), is that in the presence of nominal frictions PPP rules might facilitate the economy's adjustment to fundamental shocks.

This paper argues that there is an additional dimension along which exchange rate rules might introduce real effects. Specifically, real exchange rate targeting might open the door to endogenous aggregate fluctuations originating in arbitrary revisions of private agents' expectations. Moreover, this source of instability is likely to be welfare decreasing. Thus, governments that stand ready to devalue in response to signs of real overvaluation might indeed be creating a problem rather than solving one.

Comparing the results of this paper to those of the more traditional literature on PPP rules, there seems to emerge a tradeoff in the use of the real exchange rate as a policy target. On the one hand PPP rules can be beneficial because they may act as absorbers of fundamental shocks, such as innovations in the terms of trade or the world interest rate. On the other hand, PPP rules might generate unintended consequences by allowing for costly instability driven by non-fundamental shocks. An interesting extension of this paper would be, therefore, to evaluate this tradeoff quantitatively in the context of a full fledged general equilibrium model where both intrinsic and extrinsic sources of uncertainty are accounted for. 


\section{Appendix}

\section{Proof of Proposition 3}

It will prove convenient to define $w_{t}=c_{t}^{T} / c_{t}^{N}$ and write the equilibrium conditions (34)-(37) as

$$
\begin{gathered}
c_{t}^{T} n\left(w_{t+1}\right)=c_{t+1}^{T} n\left(w_{t+2}\right) \\
\pi_{t+1}\left(1+\pi_{t+1}\right)=\beta^{-1} \pi_{t}\left(1+\pi_{t}\right)-\frac{\theta}{\beta \phi} V^{\prime}\left(\frac{c_{t}^{T}}{w_{t}}\right)\left(\frac{c_{t}^{T}}{w_{t}}\right)+\frac{(\theta-1)}{\beta \phi} \frac{1}{n\left(w_{t}\right)} \\
w_{t}=w_{t-1}\left[\frac{1+\pi_{t}}{1+g\left(w_{t}\right)}\right] \\
\sum_{t=0}^{\infty} \frac{c_{t}^{T}}{(1+r)^{t}}=a_{0} .
\end{gathered}
$$

The proof is in two steps. First, letting $B_{*}(\delta)$ be an open ball in $R^{3}$ centered at the steadystate equilibrium $\left(c_{*}^{T}, w_{*}, \pi_{*}\right)$ with radius $\delta>0$, we show that there is a small enough $\delta$ such that for any constant allocation $\left(c^{T}, w, \pi\right) \in B_{*}$, one can find an infinite number of sequences $\left\{c_{t}^{T}, w_{t}, \pi_{t}\right\}_{t=0}^{\infty}$ satisfying (40)-(42) that converge to $\left(c^{T}, w, \pi\right)$ given an initial condition $w_{-1}$. We then invoke the technique developed in proposition 1 to argue that an infinite number of these sequences satisfy the intertemporal resource constraint (43). Thus, such sequences represent perfect foresight equilibria. Consider first the problem of characterizing solutions to (40)-(42) converging to a fixed triplet $\left(c^{T}, w, \pi\right)$. Clearly, it follows from (40) that such sequences must satisfy $c_{t}^{T} n\left(w_{t+1}\right)=c^{T} n(w)$, for $t \geq 0$. Taking this fact into account, we can 
log-linearize equations (40)-(42) around $\left(c^{T}, w, \pi\right)$ to obtain:

$$
\begin{gathered}
\hat{w}_{t+1}=-\frac{1}{\eta_{n}} \hat{c}_{t}^{T} \\
\hat{\pi}_{t+1}=\beta^{-1} \hat{\pi}_{t}-A_{1}\left(1+\eta_{V^{\prime}}\right) \hat{c}_{t}^{T}+\left[A_{1}\left(1+\eta_{V^{\prime}}\right)-B_{1} \eta_{n}\right] \hat{w}_{t} \\
\hat{w}_{t}=\hat{w}_{t-1}+\frac{\bar{\pi}}{1+\bar{\pi}}\left(\hat{\pi}_{t}-\eta_{g} \hat{w}_{t}\right),
\end{gathered}
$$

where

$$
A_{1} \equiv \frac{\theta V^{\prime}\left(c^{T} / w\right)}{\beta \phi \pi(2+\pi)}>0 \text { and } B_{1} \equiv \frac{(1+\pi)\left(\beta^{-1}-1\right)}{2+\pi}+A_{1}>0
$$

we have defined the elasticities $\eta_{n} \equiv w n^{\prime}(w) / n(w)>0, \eta_{g} \equiv w g^{\prime}(w) / g(w)>0$, and $\eta_{V^{\prime}}=x V^{\prime \prime}(x) / V^{\prime}(x)>0$. Using the above three equations to eliminate $c_{t}^{T}$ from (45) and rearranging we can write this equation and (46) as

$$
\begin{gathered}
\hat{\pi}_{t+1}=\left(A_{3}+A_{2} B_{3}\right) \hat{\pi}_{t}+B_{2} B_{3} \hat{w}_{t-1} \\
\hat{w}_{t}=A_{2} \hat{\pi}_{t}+B_{2} \hat{w}_{t-1}
\end{gathered}
$$

where

$$
\begin{gathered}
A_{2} \equiv \frac{\pi}{1+\pi+\pi \eta_{g}}, \quad B_{2} \equiv \frac{1+\pi}{1+\pi+\pi \eta_{g}} \\
A_{3}=\frac{\beta^{-1}}{1-A_{1}\left(1+\eta_{V^{\prime}}\right) \eta_{n} A_{2}}, \text { and } B_{3}=\frac{A_{1}\left(1+\eta_{V^{\prime}}\right) \eta_{n} B_{2}+A_{1}\left(1+\eta_{V^{\prime}}\right)-B_{1} \eta_{n}}{1-A_{1}\left(1+\eta_{V^{\prime}}\right) \eta_{n} A_{2}}
\end{gathered}
$$


This is a system of two equations in two unknowns, $\hat{\pi}_{t}$ and $\hat{w}_{t}$. Solutions to this system can then be used to identify $\hat{c}_{t}^{T}$ from (44). The Jacobian of the system (47)-(48) is

$$
J=\left[\begin{array}{cc}
A_{3}+A_{2} B_{3} & B_{3} B_{2} \\
A_{2} & B_{2}
\end{array}\right]
$$

Because $\hat{w}_{t}$ is a predetermined variable in period $t$ while $\hat{\pi}_{t}$ is determined in period $t$, multiple solutions of (40)-(42) converging to $\left(c^{T}, w, \pi\right)$ exist if $J$ has two eigenvalues lying inside the unit circle. As the sensitivity of the PPP rule gets large, (i.e., as $\eta_{g}$ gets large) both $A_{2}$ and $B_{2}$ converge to zero. This means that one eigenvalue of $J$ converges to zero, and the other becomes $J_{11} \equiv A_{3}+B_{3} B_{2}$. In turn, as $\eta_{g}$ gets large, $J_{11}$ becomes,

$$
\tilde{J}_{11}=\frac{\beta^{-1}-\left[(1+\pi)\left(\beta^{-1}-1\right)(2+\pi)^{-1}+A_{1}\right] \eta_{\epsilon}}{1-A_{1}\left(1+\eta_{V^{\prime}}\right) \eta_{\epsilon}}
$$

where $\eta_{\epsilon}$ is implicitly defined by $\eta_{n}=\eta_{\epsilon} \eta_{g}$. The condition $\left|\tilde{J}_{11}\right|<1$ describes the parameter configurations under which multiple solutions to (40)-(42) converging to $\left(c^{T}, w, \pi\right)$ exist as the sensitivity of the PPP rule gets large. If $\left|J_{11}\right|<1$ for $\left(c^{T}, w, \pi\right)=\left(c_{*}^{T}, w_{*}, \pi_{*}\right)$, then, by continuity $\left|J_{11}\right|<1$ for any $\left(c^{T}, w, \pi\right) \in B_{*}(\delta)$ with $\delta>0$ sufficiently small. It is now straightforward to use the arguments developed in Proposition 1 to show that an infinite number of the sequences converging to a point in $B_{*}$ and satisfying (40)-(42) will also satisfy the transversality condition (43). 


\section{References}

Arrau, Patricio, De Gregorio José, Reinhart, Carmen M., and Wickham, Peter, "The Demand for Money in Developing Countries: Assessing the Role of Financial Innovation," Journal of Development Economics, 1995, 46, 317-340.

Azariadis, Costas, Intertemporal Macroeconomics, Blackwell, Cambridge, Massachusetts, 1993.

Calvo, Guillermo A., Carmen M. Reinhart, Carlos A. Végh, "Targeting the Real Exchange Rate: Theory and Evidence," Journal of Development Economics, June 1995, 47:1 pp. $97-134$.

Dornbusch, Rudiger, "PPP Exchange Rate Rules and Macroeconomic Stability," Journal of Political Economy, 1982, 90:3 pp 158-165.

Frankel, Jeffrey. and Andrew Rose, "Currency Crashes in Emerging Markets: An Empirical Treatment," Journal of International Economics, 1996/ 41, 351-368.

Kaminsky, Graciela and Carmen M. Reinhart, "The Twin Crises: The Causes of Banking and Balance-of-Payments Problems," American Economic Review, June 1999, 89, 473-500.

Kimbrough, Kent, "The Optimal Quantity of Money Rule in the Theory of Public Finance," Journal of Monetary Economics, 1986, 18, 277-284.

Klein, Michael W. and Marion, Nancy P., "Explaining the Duration of Exchange-Rate Pegs," Journal of Development Economics, 1997, 54, 387-404.

Mendoza, Enrique G. and Uribe, Martín, "Devaluation Risk and the Business-Cycle Implications of Exchange-Rate Management," Carnegie-Rochester Conference Series on Public Policy, December 2000, 53, 239-296.

Ostry, Jonathan and Carmen M. Reinhart, "Private Savings and Terms-of-Trade Shocks," IMF Staff Papers, 39, September 1992, 495-517. 
Rebelo, S. and C. Végh, "Real Effects of Exchange-Rate-Based Stabilization: An Analysis of Competing Theories," NBER Macroeconomics Annual, 1995, 127-174, vol. 10.

Reinhart, Carmen M., and Végh, Carlos A., "Nominal Interest Rates, Consumption Booms, and Lack of Credibility: A Quantitative Examination," Journal of Development Economics, 1995, 46, 357-378.

Rudin, Walter, Principles of Mathematical Analysis, Third Edition, McGraw-Hill, New York, New York, 1976.

Uribe, M. , "Hysteresis in a Simple Model of Currency Substitution," Journal of Monetary Economics, September 1997, 40, 185-202. 